\title{
As Tecnologias de Informação e Comunicação - TIC na formação de Professores(as) em Educação Sexual: o caso das E- Oficinas na I COES
}

\author{
Célia Regina Rossi \\ Universidade Estadual Paulista (UNESP), Campus de Rio Claro, São Paulo-Brasil \\ celiarr@rc.unesp.br \\ Dilma Lucy de Freitas \\ Universidade de Lisboa, Portugal \\ dhilmalg@gmail.com
}

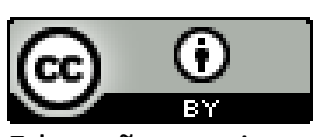

Educação: teoria e prática, Rio Claro, SP, Brasil - eISSN: 1981-8106

Está licenciada sob Licença Creative Common

\section{Resumo}

Este artigo tem por objetivo relatar como as Tecnologias de Informação e Comunicação - TIC, podem contribuir para a formação de professores(as) em educação sexual, através da experiência vivenciada com a realização das e-oficinas, que aconteceram na I Conferência on line de Educação Sexual - I COES. Essa Conferência foi organizada pela Universidade de Lisboa-PT, em parceria com a UNESPSP e a UDESC-SC. A I COES envolveu os(as) profissionais da educação, que atuam diretamente na escola, para discutirem e trocarem as suas experiências relacionadas com a educação sexual e áreas afins, através de um espaço on line. As pesquisas na área de formação inicial e continuada de professores(as) em sexualidade, educação sexual, relações de gênero e diversidade sexual têm demonstrado a necessidade de se promover e estimular os(as) professores(as) de todas as áreas a assumirem, de forma intencional e emancipatória, o seu papel de educadores(as) sexuais. Através da ferramenta de webconferência Cisco System, a I COES possibilitou a interação de noventa e cinco professores provenientes de variados pontos do Brasil e de Portugal, oportunizando ricos momentos de diálogos, problematizações e reflexões sobre as temáticas já mencionadas, referentes às realidades brasileira e portuguesa.

Palavras-chave: Educação Sexual. TIC. Formação Continuada. E-oficinas.

\section{The Information and Communication Technologies - ICT in Teacher Training in Sex Education: The Case of Workshops at I COES}

Abstract 
This article aims to describe how ICT can contribute to the training of teachers on sex education through the lived experience with the implementation of Workshops, which occurred on I COES - I Conference online of sexual education. This Conference was organized by the University of Lisbon-PT, in partnership with UNESP, SP and SC-UDESC. I COES involved education professionals, who work directly in the school to discuss and exchange their experiences related to sexuality education and related fields, through an online space. The research on teacher formation, initial and continuing on sexuality, sex education, gender and sexual diversity, have demonstrated the need to promote and encourage teachers from all areas, to adopt an intentional and emancipatory, their role as sexual educators. Through web conferencing tool Cisco System, I COES was enable the interaction and questioning of ninety five teachers from various parts of Brazil and Portugal, providing opportunities for rich moments of dialogue and reflection on the issues already mentioned, referring to the brazilian and portuguese realities.

Keywords: Sex Education. ICT. Continuing Education. Workshops.

\section{Las tecnologías de Información y Comunicación - TIC en la formación de Profesores(as) en Educación Sexual: el caso de las E-talleres en la I COES.}

\section{Resumen}

Este artículo tiene como objetivo relatar como las Tecnologías de Información y Comunicación - TIC, pueden contribuir para la formación de profesores(as) en educación sexual, a través de la experiencia vivenciada con la realización de los etalleres, que acontecieron en la I Conferencia en línea de Educación Sexual - I COES. Esa Conferencia fue organizada por la Universidad de Lisboa - PT, en colaboración con la UNESP - SP y la UDESC - SC. La I COES incluyó a los profesionales de la educación, que actúan directamente en la escuela, para discutir e intercambiar sus experiencias relacionadas con la educación sexual y áreas afines, a través de un espacio en línea. Las investigaciones en el área de formación inicial y continua de profesores(as) en sexualidad, educación sexual, relaciones de género y diversidad sexual han demostrado la necesidad de promover y estimular a los(las) profesores(as) de todas las áreas a asumir, de forma intencional y emancipadora, su papel de educadores(as) sexuales. A través de la herramienta de webconferencia Cisco System, la I COES posibilitó la interacción de noventa y cinco profesores provenientes de varios puntos de Brasil y de Portugal, propiciando ricos momentos de diálogos, problematizaciones y reflexiones sobre las temáticas ya mencionadas, referentes a las realidades brasileña y portuguesa.

Palabras clave: Educación sexual. TIC. Formación Continua. E-talleres.

\section{Introdução}


Estudos e pesquisas na área de educação sexual vêm demonstrando o quanto a inclusão de trabalhos intencionais de educação sexual na escola continua sendo uma tarefa difícil e complicada para muitos(as) professores(as). São várias as razões pelas quais essa situação se mantém. Dentre elas destacamos: a educação sexual repressora que muitos(as) professores(as) receberam e, por isso, eles(as) têm dificuldades em lidar de forma tranquila com o assunto; os preconceitos e a desinformação que aparecem acerca destas temáticas e a dificuldade na diferenciação entre os conceitos de sexo, sexualidade e educação sexual, devido, muitas vezes, a lacunas na formação inicial dos(as) professores(as). Essas dificuldades levam os(as) professores(as) ao desconhecimento de ações intencionais de educação sexual que deveriam ser desenvolvidas nas suas práticas pedagógicas de sala de aula, como apontam Rossi (2012), Ribeiro e Rizza (2012), Vianna e Unbehaum (2006). Como consequência, os(as) professores(as) trazem para o cotidiano da sala de aula o que cada um/uma entende, avalia como positivo ou negativo e importante em educação sexual, entendimentos esses permeados, muitas vezes, de conceitos somente biológicos, desconsiderando os aspectos sociais, culturais, históricos e econômicos da sexualidade.

Diante da realidade anteriomente colocada, aproveitaram-se as pesquisas recentes relativas ao potencial da Educação a Distância (EaD) e Tecnologias de Informação e Comunicação (TIC) para se ampliarem os espaços na formação de professores(as) em educação sexual, a fim de se amenizarem as dificuldades encontradas pelos(as) professores(as) que, muitas vezes, atuam solitariamente em suas salas de aula. Este texto busca mostrar que a realização da I Conferência Online de Educação Sexual - I COES, em especial os espaço abertos com as e-oficinas, pôde aproximar os(as) professores(as) de várias regiões do Brasil e de Portugal, por meio das TIC, possibilitando reflexões acerca de questões relativas à sexualidade, à educação sexual, às relações de gênero e à diversidade sexual.

O texto apontará alguns conceitos de sexualidade, de gênero e de educação sexual, objetivando reafirmar a importância na escola desses assuntos que predominaram na I Conferência Online de Educação Sexual - I COES. 
Para tal, apresentar-se-á uma breve descrição da I COES, para o entendimento dessa nova modalidade de conferência a distância e de como as novas tecnologias de informação e comunicação contribuíram como um suporte importante para a formação continuada de professores(as), nesse evento.

Por meio das TIC os(as) professores(as) tiveram contato com pessoas dos mais diferentes e distantes lugares do Brasil e de Portugal, por meio de discussões e interlocuções, sem precisarem sair de suas casas, de suas escolas. Foi uma situação confortável, agradável e diferenciada, vivenciada pelos(as) professores(as), que convivem solitariamente nas suas realidades pedagógicas. Vale ressaltar que essas realidades foram percebidas nas avaliações apontadas pelos(as) professores(as).

Todavia, o foco central deste artigo é desvelar o que atividades experienciadas dentro da I COES, mais especificamente, das e-oficinas, evidenciaram, provocaram e trouxeram às práticas pedagógicas dos (as) professores(as).

Por fim, faremos algumas considerações a respeito do estudo realizado com base nas e-oficinas realizadas na I COES, delineando possibilidades de futuras pesquisas acerca das potencialidades e do impacto das novas tecnoclogias na formação de professores(as) em educação sexual.

\section{Esclarecendo alguns conceitos}

Segundo a Organização Mundial da Saúde (in REIS \& MATOS, 2008, p.1), sexualidade caracteriza-se por:

Uma energia que nos motiva a procurar amor, o contato, a ternura, a intimidade, que se integra no modo como nos sentimos, nos movemos, nos tocamos e somos tocados; é ser sensual e ao mesmo tempo sexual. Ela influencia pensamentos, sentimentos, ações e interações com os outros e, por isso, influencia também a nossa saúde física e mental.

A sexualidade abrange $o$ ato sexual, as identidades, os papéis sociais, a orientação sexual, o erotismo, o prazer, a intimidade e a reprodução. E também é 
percebida através dos pensamentos, fantasias, desejos, opiniões, atitudes, valores, comportamentos, práticas e nos relacionamentos. Abrange a interação dos fatores biológicos, psicológicos, sociais, econômicos, políticos, culturais, éticos, legais, históricos, religiosos e espirituais, influenciando as práticas sexuais de cada grupo social (REIS \& MATOS, 2008).

A sexualidade faz parte de nossa vida, de nossa conduta cotidiana. É algo que nós mesmos criamos. Não é a descoberta de um aspecto secreto de nosso desejo e sim uma construção. Devemos compreender que, através dos nossos desejos, se instauram novas formas de relações, novas formas de amor e novas formas de sexualidade. A sexualidade é a nossa marca cultural/social, enquanto o sexo é a nossa marca biológica, mas ele não é algo fechado e pré determinado, ele é uma possibilidade de aceder a uma vida criativa (FOUCAULT, 1998).

O autor anteriormente citado (1998) afirma que a sexualidade é uma invenção social. Assim, a sexualidade pode ser compreendida como uma parte abrangente da subjetividade humana do ser masculino e ser feminino, que se faz presente em nossas posturas, emoções, atuações, sensações, saberes e pensamentos, independentemente do gênero.

Quando se pensa em gênero, pensa-se nas questões relativas à construção das masculinidades e das feminilidades. Nesse sentido, Louro aponta que a condição de ser feminino ou masculino é:

Aquilo que se diz ou se pensa sobre os indivíduos portadores de determinadas características sexuais é o que vai constituir efetivamente, o que é feminino ou masculino em uma dada sociedade e em um dado momento histórico. Os corpos são significados pela cultura e são, continuamente, por ela alterados. (2007. p.14)

Essa consideração sobre o fato de que as noções de feminino e masculino são construções socio-históricas permitiu que os atributos de feminino e de masculino 
fossem diferenciados, contribuindo para balizar uma estereotipia de percepções e significações (LIMA, 2011).

O discurso corrente, ainda hoje (apesar de todos os avanços já conquistados), sobre a sexualidade feminina, coloca as mulheres como pessoas mais frágeis, românticas, submissas, cuja "sexualidade só aflora quando é provocada e, vários são os meios de fazê-lo [...] a mulher foi socializada para conduzir-se como caça, que espera o ataque do caçador." (SAFIFIOTI, 2007, p. 27).

É esse mesmo discurso que, ao falar da sexualidade masculina, coloca os homens como fortes, diretos, racionais, induzindo muitos a acreditarem na incontrolabilidade da sexualidade masculina. Esse foi educado para ir à caça, para na condição de macho tomar sempre a iniciativa (SAFIFIOTI, 2007, p. 27), razão pela qual Simone de Beauvoir (2009, p. 12) afirmou que: "Ninguém nasce mulher, mas se torna mulher".

Nenhum destino biológico, psíquico, econômico, define a forma que a fêmea humana assume no seio da sociedade; é o conjunto da civilização que elabora esse produto intermediário entre o macho e o castrado que qualificam de feminino. Só a mediação de outrem pode constituir um individuo como outro. (BEAUVOIR, 2009, p.13).

Ou seja, homens e mulheres se constroem e resultam de um processo cultural, histórico e social. Não nascemos homens e mulheres, mas nos constituímos essas pessoas a partir da inserção em nosso universo sociocultural.

Beauvoir (2009) afirmou, ainda, que, ao tornar-se mulher, a menina encontra um caminho já traçado e que alterar essa rota é um processo difícil, porém necessário. É no enredamento de relações, forças, leituras de mundo, que nos constituímos homens e mulheres, pertencentes ao gênero masculino e feminino. 
Gênero é a forma como as características sexuais são representadas ou valorizadas, em uma determinada sociedade, em um dado momento histórico. Sendo aquilo que se diz ou se pensa sobre estas características o que constitui efetivamente o que é feminino e masculino. (LOURO, 2007, p. 21).

Falar intencionalmente de sexualidade, gênero e educação sexual na escola é abrir possibilidades aos(as) professores(as) de novos olhares a respeito do contexto histórico, social e cultural do feminino e masculino, e de como os papéis representados por mulheres e homens foram construídos na sociedade, na política, na economia e na religião. Esses papéis influenciaram essa construção ao longo dos tempos, ocasionando danos e ou distorções para os dois sexos. Entretanto, o sexo feminino, ao longo da história, foi mais demarcado pelos processos de submissão e modos de exclusão e continua a sê-lo em muitas culturas ocidentais, até os dias de hoje.

A educação sexual intencional é relativamente recente na escola, uma vez que, de forma não intencional, esta educação sempre existiu, em todos os tempos e em todos os espaços escolares, para alunos(as) e professores(as). Ela tem sido protagonizada, para além dos muros da escola, por diversos atores sociais tais como a Igreja, a família, a escola e a mídia. Mas os(as) principais atores/atrizes sociais dentro da escola devem ser os(as) alunos(as) e os(as) professores(as). Para tanto, estes(as) devem ser formados(as) continuamente, por que a sociedade está sempre em transformação, as normas e os valores se modificam e, assim, também a sexualidade e as relações de gêneros se modificam.

A educação sexual é continuadamente alvo de muitos significados, dependendo das abordagens, dos teóricos, e das linhas que a norteiam.

O termo educação sexual é ainda hoje objecto de múltiplos entendimentos ao nível do seu significado, dos seus conteúdos, da sua eficácia e consequências. Fala-se em educação sexual e informação sexual; fala-se em educação sexualizada, fala-se ainda em educação sexual e educação afectivo-sexual. Ora se encara a educação sexual como um processo marginal à construção da identidade sexual, ora se aponta aquela actividade como elemento essencial na reforma dos costumes. (RODRIGUES, FONTES, 2002, p.178) 
É perceptível nas afirmações de Rodrigues e Fontes (2002) a polêmica gerada ainda hoje acerca do termo e até mesmo do que seja o trabalho de educação sexual. Entretanto, não é possível deixar de considerar que somos todos(as) seres sexuados(as) desde o nascimento, que a educação é um processo que acontece continuamente, por meio da troca de experiências e de conhecimentos entre os seres humanos e, através do qual, todos(as) educam e são educados(as).

Freire relata que "ninguém educa ninguém, os homens se educam em comunhão." (1981, p. 79). Partindo dessa premissa, considera-se que a educação sexual, assim como todas as outras, acontece desde o nascimento e num processo contínuo de trocas de conhecimentos e de experiências sociais, históricas e culturais. Portanto, de forma não intencional, educamos e somos sexualmente educados(as).

Essa educação é realizada com palavras, ações intencionais ou olhares, gestos, expressão dos sentimentos, atitudes, exemplos que propiciamos para os(as) outros(as) e até mesmo $\mathrm{cm}$ coisas sobre as quais não falamos, ou seja, com o silêncio. Silêncio esse que "já indica um compromisso terrível: o de não comprometer-se com a transformação da ordem para que tudo continue como está." (GOLDERBERG, 1988, p. 93). Já para Nunes este silêncio é muitas vezes “a medida da repressão" (1987, p. 116). Vivemos em uma sociedade que traz como marca histórica a repressão sexual. Nela, a educação sexual intencional em uma perspectiva emancipatória deve necessariamente rever criticamente a norma sexual hegemônica repressiva, vigente na nossa cultura, para problematizá-la e transformá-la.

A educação sexual, numa perspectiva emancipatória ou "combativa", deve abranger uma abordagem política e um compromisso com a transformação política, cultural, social e educacional. A abertura de espaços formais de diálogos e reflexões críticas na família, na escola, nos clubes, nas igrejas, nas redes sociais através da internet, da mídia etc., tem como objetivo questionar criticamante e buscar superar a repressão sexual, em função da qual a sexualidade se constituiu na cultura ocidental (FIGUEIRÓ, 2001). 
A educação sexual intencional numa perspectiva emancipatória é importante na escola, por desvelar todas as formas de sexualidade existentes nos papéis que homens e mulheres podem desempenhar na sociedade, papéis que são múltiplos e que devem ser equitativos e igualitários. $O(a)$ professor(a) dentro da escola pode desempenhar o papel de inquietador dos(as) alunos(as), problematizando os vários papéis que os homens e as mulheres podem desempenhar, fruto de suas construções políticas, com a livre escolha, que fazem ao longo da vida. Na escola, o(a) professor(a) é, sobretudo, alguém que atua com os conhecimentos, portanto, sofre diretamente as crises pelas quais passam tanto o processo de produção de saberes, quanto o processo de transmissão de saberes. Deste modo, é necessário avaliar qualquer pretensão massificante da pedagogia, pois o processo educativo precisa ser voltado para uma subjetividade autônoma, resultante de diferentes pedagogias em exercício (GALLO, 2004).

Dentro dessas premissas, mais uma vez se evidencia a importância do processo de formação continuada dos(as) professores(as), nas temáticas ligadas à sexualidade, educação sexual, relações de gênero e diversidade sexual. Levando em consideração a defasagem existente na formação inicial da maioria deles, entendemos que a I COES ampliou os espaços para a sua formação, possibilitando emergirem temáticas importantes para a construção de novas maneiras de se atuar em sala de aula.

\section{As TIC como potencializadoras de formação continuada em educação sexual}

A sociedade atual coloca constantemente a necessidade e o desafio de estarmos num processo de atualização e de aprendizagem contínua. As tecnologias cada vez mais rápidas e integradas podem contribuir para que esses desafios e necessidades sejam, pelo menos em parte, satisfeitos. Desde o surgimento da World Wide Web, comumente conhecida por WWW ou Web 2.0, no final da década de 80, que teve como proposta o compartilhamento e a criação de novos conhecimentos através de redes sociais e de conteúdos colaborativos, a educação on line ganhou 
também grande destaque. Por educação on line Moran (2003) ${ }^{1}$ entende um conjunto de ações de ensino-aprendizagem desenvolvidas por meios telemáticos, como a Internet, a videoconferência e a teleconferência.

Com o desenvolvimento da internet provocando grandes "mudanças ocorridas na nova sociedade da informação, a educação é convocada a assumir um papel fundamental na produção de conhecimentos por meio do uso das tecnologias" (BRENNAND e GUIMARÃES, 2007, p. 178). A junção das tecnologias com a educação abre novos espaços e possibilidades de aquisição de saberes e, consequentemente, de espaços de formação continuada através da EaD. Dentre as propostas e programas de formação continuada de professores(as), vinculadas às universidades, pode-se destacar a EaD como uma das políticas educacionais mais relevantes na atualidade, políticas essas que vêm apresentando esforços significativos tanto de investimento teórico, quanto financeiro, realizados pelas universidades e pelo poder público, respectivamente.

Muitos são os questionamentos dessa modalidade de formação de professores(as), principalmente pelo caráter inovador e inicial das propostas vivenciadas pelas universidades. Aproveitando esses investimentos realizados pelas universidades e o espírito questionador, inovador e desafiador de um grupo de pesquisadoras de uma universidade portuguesa e de duas universidades brasileiras, organizou-se, em parceria, a I Conferência On line de Educação Sexual - I COES.

\section{Uma breve apresentação da I COES}

A I COES aconteceu nos dias 2, 3 e 4 de maio de 2012, na modalidade totalmente online e, como já foi mencionado, foi organizada pelo Instituto de Educação da Universidade de Lisboa (IEUL), em parceria com a Universidade Estadual Paulista "Júlio de Mesquita Filho" (UNESP/BR) e a Universidade do Estado de Santa

\footnotetext{
${ }^{1}$ MORAN, J. M. Contribuições para uma pedagogia da educação online. In: SILVA, M. (Org.). Educação online: teorias, práticas, legislação, formação corporativa. São Paulo: Loyola, p. 39-50, 2003. Disponível em: http://www.eca.usp.br/moran/contrib.htm Acessado em 21/10/2012 - 13:00 h.
} 
Catarina (UDESC/BR). As trocas de experiências e de parcerias existentes entre os três Grupos de Pesquisa destas Universidades - Grupo de Estudos e Investigação em Sexualidade e Tecnologias - GEISEXT (IEUL), Grupo de Pesquisa e Extensão sobre Sexualidades - GSEXs (UNESP) e Grupo de Formação de Professores e Educação Sexual - EDUSEX (UDESC) - vinham demonstrando a necessidade de se ampliarem os espaços de formação, diálogo e de reflexão entre os(as) professores(as) sobre a sexualidade, a educação sexual, as relações de gênero e a diversidade sexual na escola.

Vários estudiosos da área apontam que as temáticas de sexualidade têm sido pouco valorizadas, trabalhadas e discutidas na escola (GOLDBERG, 1988; FIGUEIRÓ, 2001). Corroborando com esses estudiosos, constatatou-se, por pesquisas realizadas pelos grupos de pesquisa, estudo e extensão em educação sexual das três universidades parceiras da I COES, que os poucos trabalhos realizados nas escolas são feitos primordialmente, pelos(as) profissionais das áreas da saúde - médicos(as) e enfermeiros(as) - e da área da psicologia, convidados(as) esporadicamente pelas instituições escolares para realizarem palestras. Quanto aos professores(as) que têm realizado esses trabalhos, na maioria dos casos, são aqueles(as) que estão ligados(as) ao ensino das ciências biológicas, focando o trabalho mais no campo biológico, do que nos campos social, cultural e histórico. Razão pela qual a I COES teve o objetivo de integrar as áreas da saúde com as áreas da educação e, principalmente, promover e estimular os(as) professores(as) de todas as áreas a assumirem, de forma intencional e emancipatória, o seu papel de educadores(as) sexuais, independentemente da área de atuação curricular e da faixa etária em que lecionavam.

Objetivou-se reunir professores(as) de todos os níveis e áreas de ensino, assim como pesquisadores(as), interessados(as) em ampliar os seus conhecimentos nas diferentes áreas, por meio da partilha de experiências, de pesquisas, de problematizações, assim como de inquietações que têm acompanhado todos(as) os(as) que atuam com as temáticas da sexualidade, com vista à realização de trabalhos intencionais de educação sexual numa perspectiva social, cultural e histórica, na instituição escolar. 
Como esse foi o primeiro evento nessa área temática, organizado totalmente online, em Portugal e no Brasil, enfrentaram-se os desafios comuns a tudo o que é inovador, nomeadamente: as inseguranças; as incertezas; o desconhecimento acerca de algumas questões, em especial as tecnologias, e a falta de modelos para apoio da I COES.

A I COES teve como resultado duzentos e quinze pré-inscritos(as) no seu site (www.coes2012.com), mas apenas noventa e cinco professores(as) efetivaram a inscrição e participaram ativamente da I Conferência. Por parte de Portugal, se inscreveram trinta e cinco professores(as): Lisboa, Porto, Coimbra, Setúbal, Viseu e Madeira. De Cabo Verde, na África, uma professora se inscreveu. Do Brasil, cinquenta e nove professores(as) se inscreveram, sendo: trinta e três da região sul, vinte e um da região sudeste, dois da região centro oeste, dois da região nordeste e um/a professor/a da região norte. Houve a representação de todas as regiões do Brasil nesta Conferência.

Esta Conferência foi organizada à luz de referenciais teóricos que pudessem apontar a importância das TIC para a formação de professores(as) no que tange às temáticas da sexualidade. Ela foi construída com a participação, trabalho, atuação, mediação e avaliação de todas as integrantes dos grupos de pesquisa, estudo e extensão das três universidades. Seu programa foi organizado em quatro momentos diferenciados: as webconferências, as salas temáticas, os relatos de experiências e as e-oficinas. Em cada dia do evento aconteceram: i) uma webconferência tendo como temas: A Educação Sexual no espaço escolar; A multiculturalidade e a educação sexual na escola e Reflexões sobre a possibilidade da educação sexual intencional nas instituições escolares; ii) quatro salas temáticas com os temas focados em diferentes áreas, nomeadamente: sexualidade e gênero, sexualidade e adolescência, sexualidade infantil, sexualidade e deficiência, formação de professores(as), violência sexual, políticas públicas de educação sexual no Brasil e em Portugal, educação sexual e o combate à homofobia e metodologias de educação sexual na escola; iii) três ou quatro 
relatos de experiências focando os eixos temáticos da I COES e, em período oposto ao evento, as três ou quatro e-oficinas.

As e-oficinas ocorridas na I COES tiveram como objetivo levar o(a) professor(a) a refletir criticamente por meio de atividades práticas, diálogos, problematizações, jogos, leituras, exercícios e dinâmicas, as temáticas da sexualidade, abordadas nas salas temáticas e nas webconferências. As atividades realizadas e as experiências vivenciadas foram muitas, e seriam vários os aspectos a serem compartilhados e refletidos neste texto, mas, como foi referido acima, optou-se por fazer um recorte da Conferência e detalhar a experiência das e-oficinas que trouxeram alguns dados significativos observados pelas pesquisadoras. No entanto, para além deste, pretendese elaborar outros textos para apresentar os vários trabalhos realizados na I COES e os resultados obtidos por meio das análises dos dados das avaliações dessa Conferência.

\section{As E-oficinas}

Ao planejar as atividades que seriam desenvolvidas na I COES, pensou-se ser importante propor atividades que a aproximassem o máximo possível de um evento presencial, diminuindo, desta forma, o impacto que um evento totalmente online pudesse causar, uma vez que, os(as) professores(as) não eram acostumados a esse tipo de evento. Nesse sentido, decidiu-se pela realização das e-oficinas por uma série de razões, das quais destacaram-se duas: i) a possibilidade de propiciar uma maior aproximação entre os(as) professores(as) participantes, diminuindo assim o distanciamento que, por ventura, um evento totalmente online pudesse ocasionar; ii) abrir um espaço de socialização e reflexão crítica de teorias e práticas acerca de algumas temáticas, relacionadas com a educação sexual no espaço escolar. Optou-se por usar o "e" antes da palavra oficina como forma de marcar a sua realização eletrônica, através da Web 2.0 .

Como a I COES era o primeiro evento totalmente online nessa área temática, não se sabia ao certo como seria a receptividade dos(as) professores(as) acerca das eoficinas, nem se tinha a menor ideia de quantos(as) seriam os(as) inscritos(as). Assim, 
a preocupação foi garantir aos participantes um espaço onde pudessem interagir com mais proximidade e que fosse capaz de estimular a participação ativa, criativa, interativa e colaborativa, possibilitando a socialização dos fundamentos teóricos e práticos que cada um deles(as) possuía e facilitando, assim, o processo de ensinoaprendizagem acerca das temáticas das e-oficinas.

Considerando-se, conforme Zenaide (2005), que a construção metodológica de uma oficina deve possibilitar espaços reflexivos, a formação de vínculos entre os(as) participantes, a comunicação interativa, a partilha de conhecimentos práticos e teóricos e a reflexão crítica do conhecimento produzido, iniciou-se a organização das e-oficinas. O objetivo era o de oferecer aos participantes a oportunidade de realizarem atividades práticas relacionadas com os temas do seu interesse. Naquele espaço, apoiados pelos(as) dinamizadores(as), poderiam construir algumas atividades, dinâmicas ou recursos que pudessem ser reutilizados em situações futuras, no seu espaço escolar.

O impacto inicial foi de insegurança e receio do desconhecido, o que foi também destacado nas experiências relatadas por Loch \& Reushle (2008), Schroeder (2007) e Virtartas, Rowe \& Ellis (2008). À medida que se ambientavam com a nova ferramenta, com o novo "espaço", e que se deparavam com outros(as) professores(as) e pesquisadores(as), todos(as) em busca de novas possibilidades de refletir educação sexual, a segurança necessária foi sendo construida, trocando a insegurança inicial pelo prazer de uma aprendizagem diferenciada e inovadora.

A metodologia usada para que as e-oficinas obtivessem melhor resultado, foi definir um número mínimo e máximo de participantes. Definiu-se, então, que o número mínimo de participantes por e-oficinas seria de quatro e o máximo seria de doze pessoas; as e-oficinas teriam até duas horas de duração, o mesmo tempo médio de uma oficina presencial.

Por saber-se da necessidade e da importância de todos(as) conhecerem antecipadamente o funcionamento da ferramenta, para o sucesso da atividade proposta, como apontam Morgan, Hurst \& Streff (2010), Virtartas, Santos \& 
Nascimento (2011), Vitartas; Rowe \& Ellis (2008), Molina (2012), duas semanas antes do início da Conferência, programou-se o treinamento tanto com os(as) dinamizadores(as) quanto os(as) inscritos(as) nas e-oficinas, para que eles(as) se apropriassem da ferramenta e preparassem seus computadores instalando os plugins necessários.

Com os plugins instalados, todos(as) familiarizados(as) com os equipamentos, com a equipe de trabalho e com os temas definidos, onze e-oficinas foram ministradas ${ }^{2}$. Aconteceram quatro e-oficinas por dia, tendo como temas: i) Ficar, pegar, transar: de que forma essas palavras apresentam a sexualidade dos adolescentes e jovens e como elas repercutem em suas famílias. Um exercício de diálogo para lá de necessário; ii) Meninos versus Meninas: representações de gênero em uma reportagem de revista para adolescentes; iii) Corpos, gênero e sexualidades: dos currículos escolares aos espaços educativos; iv) A utilização de vídeos do site Youtube para trabalhar conteúdos de Educação Sexual no Ensino Pré-escolar e Básico; v) Reflexões sobre a Declaração dos Direitos Sexuais como Direitos Humanos Universais; vi) A mídia e a adultização da infância e da adolescência; vii) Corpos, gênero e sexualidades: dos currículos escolares aos espaços educativos; viii) Famílias homoparentais, homossexualidades e educação; ix) Conversando sobre sexualidade com professores e professoras; $x$ ) Tamanho é documento? Uma análise da sexualidade, educação sexual e formação docente, através de desenhos infantis; xi) Convivendo com SIDA/AIDS no contexto escolar.

Das onze e-oficinas oferecidas, duas acabaram não acontecendo em função de problemas técnicos ocorridos ao ser programada a abertura das salas das webconferências. Esse problema fez que as atividades se iniciassem com certo atraso, levando alguns participantes das e-oficinas em questão a desistirem de esperar, o que culminou com a não realização das mesmas. Convém ressaltar que o problema ocorrido não impediu que as outras e-oficinas desse dia fossem realizadas com êxito. 0

\footnotetext{
${ }^{2}$ Maiores detalhes das e-oficinas estão no link:

http://www.coes2012.com/atividades/programa/dia1.aspx
} 
número de participantes em cada uma variou entre quatro e onze. A maioria delas teve um número médio de oito professores(as).

Essas e-oficinas foram importantes porque desvelaram o quanto os(as) professores(as) estão sedentos de conhecimentos claros e científicos nessa área. Desvelaram, da mesma forma, o quanto ainda trazem para suas práticas de sala de aula o que viveciaram na família, na igreja e no cotidiano de suas relações sociais, bem como os poucos conhecimentos trazidos da sua formação inicial.

A maioria dos conhecimentos levados para a sala de aula são inadequados, equívocados e permeados de preconceitos, como apontam estudos de Louro (2003). As falas e práticas levadas para a sala de aula são frequentemente pautadas em experiências de vida repletas de preconceitos, equívocos, medos, críticas infundadas, distorcidos da realidade dos(as) alunos (as) e, às vezes, também de violência. Os riscos dessas práticas dizem respeito à possibilidade de, em algumas dessas situações, se criarem modos de exclusão, se gerarem mais preconceito e se fixarem valores distorcidos e incorretos nesse tipo de trabalho com educação sexual, na medida em que os(as) professores(as) não possuem uma base científica.

Das dezoito respostas obtidas dos(as) participantes sobre a satisfação das suas expectativas em relação às e-oficinas, o resultado foi que quinze colocaram que estão plenamente satisfeitos(as), duas colocaram estar parcialmente satisfeitas e apenas uma, que correspondeu a uma professora que estava inscrita na e-oficina que não aconteceu, respondeu que a e-oficina deixou a desejar.

Por parte dos dinamizadores(as), o resultado apontado foi que, dos nove que até o momento das análises responderam ao questionário, seis colocaram que estavam plenamente satisfeitos e três parcialmente satisfeitos. Os motivos das insatisfações explicitadas foram dois: o baixo número de participantes em algumas eoficinas e a falta de possibilidade, por razões de tempo, de se explorarem mais os recursos da ferramenta da CISCO.

Dentre as dificuldades encontradas, para além dos problemas técnicos já referidos, foram colocadas outras questões do tipo: "a diferença de fusos horários", 
"gerir o tempo disponível; selecionar a informação transmitida aos participantes (préconferência)" e "alguma falta de experiência nesses tipos de intervenções".

Os aspectos positivos superaram em muito os negativos e ficou registrado, de variadas formas (para além das gravações e do questionário, deixaram registros nas páginas das redes sociais, enviaram e-mails, dentre outras mais), o encantamento acerca do potencial e de todas as possibilidades que as tecnologias ofereceram com relação à abertura de espaços de discussão e reflexão sobre as temáticas da sexualidade, relação de gênero, violência, diversidade sexual e da construção da sexualidade na infância e na adolescência.

Foi destacada, em especial, a possibilidade de aproximação de pessoas dos mais distantes lugares do mundo em um mesmo espaço, oportunizando o diálogo com renomados(as) pesquisadores(as) acerca das temáticas em questão. Com esta aproximação de professores(as), alunos(as) de graduação e pós graduação, foi manifestada a vontade de perguntar, a vontade de saber, a vontade de apontar, a vontade de problematizar questões tão poucos discutidas nas escolas.

Lévy aponta que, "por intermédio de mundos virtuais, podemos não só trocar informações, mas verdadeiramente pensar juntos, pôr em comum nossas memórias e projetos para produzir um cérebro cooperativo." (1998, p.96). Esse foi o caso das eoficinas da I COES que, através de temáticas significativas e relevantes, possibilitaram as trocas de informações e as problematizações de questões relativas à educação sexual, que, em muitos casos, os(as) professores(as) têm dificuldades em mediar de forma tranquila e numa perspectiva emancipatória, devido à falta de formação inicial e continuada.

Observou-se, com essas e-oficinas, a necessidade de mais investimentos na preparação dos dinamizadores(as) para o uso da ferramenta, bem como nas estratégias pedagógicas relativas a esse tipo de atividade (oficinas on line), ainda tão novas para todos nós. Contudo, elas apresentaram algumas estratégias pedagógicas relativas ao trabalho intencional de educação sexual na escola, que evidenciaram terem sido úteis para a prática pedagógica dos(as) professores(as). O feedback 
recebido pelos(as) mesmos(as) confirma que as trocas e os debates foram muito interessantes, importantes e inovadores em todas as e-oficinas, suscitanto muitas questões que foram compartilhadas e refletidas pelos grupos.

Através das gravações e do questionário final (semiestrurado) das e-oficinas, os dados revelaram que espaços reflexivos foram abertos, que a partilha de conhecimentos práticos e teóricos aconteceu, que a comunicação interativa também ocorreu e que houve uma formação de vínculos entre os(as) participantes.

Concluiu-se que o objetivo de oferecer aos participantes a oportunidade de realizarem atividades práticas foi alcançado, na medida em que trinta e oitos dos quarenta e três formulários respondidos destacaram que as e-oficinas contribuíram para os participantes vislumbrarem novas estratégias pedagógicas para trabalhar de forma intencional e emancipatória a educação sexual na escola.

Através deste espaço, os(as) professores(as) tiveram acesso não somente aos conhecimentos científicos produzidos na área da educação sexual, mas também a alguns recursos didático-pedagógicos, que irão auxiliá-los(as) na realização desse trabalho com mais confiança, tranquilidade e dentro de uma perspectiva de respeito às diferenças e às diversidades.

\section{Considerações finais}

A constatação da importância e da necessidade de se abrirem espaços de discussão a respeito das temáticas que envolvem a sexualidade, possibilitando que questões emergentes relativas a elas sejam compartilhadas e refletidas com os professores(as), levou-nos a organizar a I Conferência Online de Educação Sexual - I COES. Ressalta-se a relevância da abertura desses espaços como forma de colaboração com a comunidade escolar no sentido de se repensar e reconstuir o trabalho de educação sexual na escola, realizando-o de forma segura, equitativa, fundamentada e "politicamente correta".

$\mathrm{O}(\mathrm{a})$ professor(a) amplia as suas possibilidades de atuar na escola, ao repensar e reconstruir os seus conceitos e pré conceitos relativos às temáticas da sexualidade, 
utilizando os recursos disponibilizados pelas novas tecnologias. Isto porque, para além desta mudança, coloca-se mais próximo de seu(sua) aluno(a) que, fazendo parte da geração dos "nativos digitais", muitas vezes tem acesso e domina essas tecnologias com mais frequência e tranquilidade do que o(a) professor(a).

A análise dos dados recolhidos com as e-oficinas da I COES possibilitou perceber o desvelamento da educação sexual intencional aos(às) professores(as) de maneira mais concreta. Verificou-se a construção de novos olhares, agora mais críticos e construtivos sobre a sexualidade e a educação sexual, por meio da problematização fundamentada acerca dos preconceitos e exclusões sociais desencadeados por estes temas. Almeja-se que esses novos olhares possam ser levados e revistos na escola, gerando-se propostas de trabalhos dentro dos Projetos Políticos Pedagógicos - PPPs. Por meio de relatos, indagações, pontuações e avaliações das e-oficinas, os(as) professores(as) apontaram que as políticas públicas de educação sexual precisam ser revistas urgentemente e que, na formação inicial e continuada, a temática da sexualidade precisa ser melhorada e mais considerada.

Acentua-se a importância das e-oficinas realizadas na I COES como novos e importantes espaços na formação contínua de professores(as), que podem servir como consideráveis instrumentos de mudanças no âmbito escolar. Porém, não podemos esquecer que o(a) professor(a), mesmo sendo uma das chaves para a mudança, necessita de um trabalho conjunto com o(a) gestor(a) da escola, a família, os(as) funcionários(as), juntamente com as políticas governamentais de educação de seu país, estado, município e comunidade.

É necessário aproveitar e utilizar todo o potencial disponibilizado pelas novas tecnologias, no sentido de se criarem e reinventarem novas formas para se minimizar a defasagem existente na formação inicial e contínua de professores(as) em educação sexual. Por intermédio dessas ações, será desenvolvido nos(as) professores(as) o

\footnotetext{
3 Expressão utilizada pelo pesquisador Marc Prenky (2001) para designar os nascidos a partir do desenvolvimento da web 2.0. (In PESCADOR, C.M. Tecnologias Digitais e Ações de Aprendizagem dos Nativos Digitais. 2010. Disponível em: http://goo.gl/E0GhAf Acessado em 25/07/2013.)
} 
respeito pelo ensino laico, de modo que eles(as) venham a realizá-lo sem preconceitos, evitando qualquer tipo de exclusão e violência, visando à construção de uma sociedade mais justa, digna e igualitária.

Considera-se a realização da I COES e, mais pontualmente, das e-oficinas, como uma dessas importantes e relevantes iniciativas, ainda carente de algumas melhorias na sua segunda edição, que irá se realizará em 2013. Ressalta-se, também, a pertinência desse trabalho para a abertura e ampliação de novas experiências e pesquisas, que poderão contribuir para a criação de diferentes estratégias na formação continuada de professores(as) em educação sexual, diversidade sexual e relações de gênero, dentre outras questões emergentes da sexualidade. 
Referências Bibliográficas

ALMEIDA, J. F. F. e BRENNAND, E. G. de G. A educação a Distância na era da sociedade em rede. Educação Pesquisa, vol. 29, n 2, São Paulo. Jul/Dec. 2003.

BEAUVOIR, S. O segundo sexo. Volume Unico. São Paulo: Nova Fronteira, 2009.

BRENNAND, E. G. de G.; GUIMARÃES, J. M. de M. Educação a distância: a "rede" eliminando fronteiras. João Pessoa: Editora Universitária, 2007.

FIGUEIRÓ, M. N. D. Educação sexual: retomando uma proposta, um desafio. Londrina: Ed. UEL, 2001.

FOUCAULT, M. Historia da sexualidade I: a vontade de saber. Tradução Maria Thereza da Costa Albuquerque e J.A Guilhon Albuquerque. Rio de Janeiro: Graal, 1998.

FREIRE, P. Ação cultural para a liberdade. Rio de Janeiro: Paz e Terra, 1981.

GALLO, S. Etica e cidadania: caminhos da filosofia. Campinas: Papirus, 2004.

GOLDBERG, M. A. A. Educação sexual: uma proposta, um desafio. 4. ed. São Paulo: Cortez, 1988.

LIMA, M. T. M de O. Entre tapas e beijos quais as possibilidades? Tessituras nas relações de gênero em uma escola do Ensino Fundamental II. 2011. Dissertação (Mestrado em Educação) - Departamento de Educação -Instituto de Biociências do Campus de Rio Claro, Universidade Estadual Paulista, Rio Claro, 2011.

LOCH, B. \& REUSHLE, S. The practice of web conferencing: Where are we now? In: Hello! Where are you in the landscape of educational technology? Proceedings ascilite. Melbourne. 2008.

http://www.ascilite.org.au/conferences/melbourne08/procs/loch.pdf Acessado em 27/12/2012.

LOURO, G. L.; NECKEL, J.F.; GOELLNER, S. V. (Orgs). Corpo gênero e sexualidade: um debate contemporâneo na educação. Petrópolis: Vozes, 2003.

Pedagogias da sexualidade. In: (Org.). 0 corpo educado. Belo

Horizonte: Autêntica, 2007. 
MOLINA, P. Case Study 12: Georgetown University: Web Conferencing. A Critical Skill for the Connected World. In: OBLINGER, D. G. Education and Information

Technologies. Washington, D.C.: EDUCASE, 2012.

http://www.educause.edu/library/resources/case-study-12-georgetown-universityweb-conferencing\%E2\%80\%94-critical-skill-connected-world Acessado em 13/11/2012

MORAN, J. M. Contribuições para uma pedagogia da educação online. In: SILVA, M. (Org.). Educação online: teorias, práticas, legislação, formação corporativa. São Paulo: Loyola, 2003. p. 39-50. Disponível em: http://www.eca.usp.br/moran/contrib.htm Acessado em 21/10/2012 - 13:00 h.

MORGAN, R; HURST, L. \& STREFF, B. The Evolving Use of Web-Conferencing Technology in Childcare Practitioner Education. Chicago, 2010.

http://www2.ed.gov/about/inits/ed/earlylearning/public-comments-chicago.pdf Acessado em 23/11/2012.

NUNES, C. A. Desvendando a sexualidade. Campinas: Papirus, 1987.

PIERRE, L. A máquina universo: criação, cognição e cultura Informática. Porto Alegre: Artmed, 1998.

REIS, M. \& MATOS, M. (2008). Contracepção em jovens universitários portugueses. Disponível em: http://www.scielo.oces.mctes.pt/pdf/aps/v26n1/v26n1a06.pdf Acessado em: 18/10/2012.

RIBEIRO, P. R. C.; RIZZA, J. L. Educação para a Sexualidade: formação inicial de professores(as) em um ambiente virtual de aprendizagem. In: SOUZA, C. B. G.; RIBEIRO, P. R. M. Políticas Públicas em educação no contexto ibero-americano. São Paulo: Cultura Acadêmica, 2012. p. 173-189.

RODRIGUES, I. T.; FONTES, A. Indentificação do papel da escola na educação sexual dos jovens. Investigações em Ensino de Ciências, Porto Alegre, UFRGS, v. 7 (2), p. 177-188, 2002.

ROSSI, C. R. As políticas públicas de sexualidade no Brasil: a relevância da implementação de um curso de formação continuada de professores da rede básica de educação pública, a experiência da UNESP, campus de Rio Claro. In: SOUZA, C. B. G.; RIBEIRO, P. R. M. Políticas Públicas em educação no contexto ibero-americano. São Paulo: Cultura Acadêmica, 2012. p. 117-124.

SAFIFIOTI, H. Gênero, patriarcado, violência. São Paulo: Ed. Fundação Perseu Abramo, , 2007. 
SANTOS, A. R. \& NASCIMENTO, E. L. A webconferência como instrumento de ensinoaprendizagem nos cursos a distância. IV Encontro Nacional de Hiper Texto e Tecnologias Educacionais. 2011.

http://www.uniso.br/ead/hipertexto/anais/11 AnnieSantos.pdf Acessado em 04/01/2013.

SCHROEDER, S. Microsoft Live Meeting 2007: Web Conferencing System for Virtual Classrooms. 2007.

http://innovateonline.info/pdf/vol1 issue1/Rethinking Space and Time-

The Role of Internet Technology in a Large Lecture Course.pdf Acessado em 28/11/2012.

VIANNA, C; UNBEHAUN, S. Gênero na educação Básica: quem se importa? Uma análise de documentos de políticas públicas no Brasil. Educação \& Sociedade, Campinas, v. 27, n. 95, p. 407-428, maio/agosto 2006.

VIRTARTAS, P.; ROWE, S. and ELLIS, A. Student's first experiences with a Web conferencing system: preliminary findings. 2008.

http://ausweb.scu.edu.au/aw08/papers/refereed/vitartas/paper.html Acessado em 09/12/2012.

ZENAIDE, M. de N. T. A Oficina Pedagógica como recurso na educação em Direitos Humanos. In: RIQUE, C.; LIMA, N. de. (Orgs.). Juntando saberes e construindo práticas. Recife: Bagaço, 2005. p. 21-30.

http://www.gajop.org.br/arquivos/publicacoes/Juntando saberes e construindo \%2 Opraticas.pdf Acessado em 10/12/2012.

Enviado em Abril/2013

Aprovado em Julho/2013 